Brit. J. industr. Med., 1956, 13, 281.

\title{
DERMATITIS IN COAL-MINERS
}

\author{
BY \\ ARTHUR ROOK and GEOFFREY HODGSON \\ From Addenbrooke's Hospital, Cambridge, and United Cardiff Hospitals
}

(RECEIVED FOR PUBLICATION AUGUST 24, 1955)

\section{The Size of the Problem}

Occupational skin disease in coal-miners in Great Britain is an important medical and economic problem. The report of H.M. Chief Inspector for Mines (1950) shows the steady increase in the number of certificates of disablement for industrial dermatitis given under the Workmens Compensation Act from 402 in 1940 to 1,650 in 1947, and 1,588 up to July 5,1948 . From that date the certificates given for dermatitis under the National Insurance (Industrial Injuries Prescribed Diseases) Regulations, 1948, continued to increase to 3,100 in 1949, the last year for which figures are given in this report. These statistics cover all persons employed in the coal-mining industry, reaching a peak of 750,300 in 1944 , but falling to 747,000 by the following year.

During the period 1940-44 the dermatitis certification rate per 1,000 workers employed underground in Great Britain rose from 0.7 to 5.1 and in the South Western Region from 0.6 to $6 \cdot 6$. The dermatitis certification rate for all employees for the years 1946-50 can be calculated from the total number of employees given in the report of the Chief Inspector of Mines, and shows an increase from 2.4 per 1,000 total employees in 1946 to 4.2 per 1,000 in 1949. Unfortunately, comparable figures for underground workers only to give a more exact picture are unobtainable.

Squire, Cruickshank, and Topley (1950) were able to show that in the engineering industry the actual incidence of dermatitis is higher than the certification rate indicates as many workers do not report the less severe attacks. The same is certainly true of the mining industry, and it is our experience that some miners continue at work even with extensive dermatitis. The statistics quoted, therefore, define the extent of the economic problem of industrial dermatitis but underestimate the size of the medical problem, for which no figures are yet available. Squire and his colleagues also drew attention to the fact that more certificates for dermatitis had been issued in all industries, even in those in which no technological changes have been introduced. They suggested that the increase might be more apparent than real and might be due to a greater willingness on the part of the worker to stop work as a result of improved social security.

Although it is the opinion of many practitioners in coal-mining districts that there has been a real and substantial increase in the incidence of dermatitis, there is no proof that such is the case and the actual incidence of dermatitis is unknown.

\section{The Literature}

The diseases of miners have attracted the interest of medical men from the earliest times. The history of miners' diseases has been comprehensively reviewed by Rosen (1943), but skin diseases in miners are rarely mentioned in the earlier literature. Ramazzini (1746) has two brief references. He refers to injury to the skin of the lower legs in those working in water, and also mentions what appears to be a form of skin ulceration. Incidental references to pustular eruptions are occasionally encountered but other diseases are rarely recorded. Thackrah (1832) makes no specific mention of skin diseases. Boëns-Boissau (1862), in his volume on the diseases and accidents of Belgian coal-miners, states specifically that skin diseases are less common in miners than one expects from the nature of their occupation. He devotes six pages to the skin and discusses ringworm, scabies, zoster, acne, bursitis, and eczema, but does not suggest that any is related to the occupation. The monograph of the Belgian, Kuborn (1863), mentions 36 affections of the skin in a group of 1,518 miners but gives no details.

The authoritative works on occupational skin disease of the present century devote little attention to miners. Prosser White (1915) gives only a very brief reference to pigmented scars. Schwartz, Tulipan, and Peck (1947) devote less space to miners and workers in related occupations than to the theatrical profession and motion picture industry. 
Heymann and Freudenberg (1925) published a detailed statistical study of the morbidity and mortality of Ruhr miners, but he made no reference to dermatitis. A United States Public Health Service Bulletin (Flinn, Seifert, Brinton, Jones, and Franks, 1941) devoted to the health of soft-coal-miners is naturally mainly concerned with silicosis. "Other occupational hazards did not appear to be of significance ... . Miners' nystagmus, bursitis, and allied conditions were not observed." This negative evidence suggests that dermatitis in miners has become a more serious problem in recent years and that the incidence may differ from country to country.

Dowling and Brain (1934) described an outbreak of a widespread pustular eruption which affected about 100 miners in a hot pit.

Knowles (1944) investigated the factors influencing dermatitis in a group of nine pits in the Chesterfield area, employing 7,700 men. Fifty-six cases of dermatitis occurred in two years. The depths, wet and dry bulb temperatures, or humidity, did not influence the incidence, nor was it higher in wet pits than in dry. The importance of water, dust, trauma, and constitutional factors is emphasized but the number of cases was too small for any conclusions to be drawn as to the relative importance of the various factors.

Holčík (1952) of Czechoslovakia examined miners in pithead baths. He found tinea pedis in almost $50 \%$, and more frequently in the younger miners, irrespective of the duration of employment. Furunculosis was present in $7 \%$, occurring mainly during the first two years underground. High environmental temperatures and poor ventilation were contributory factors. Contact dermatitis was mainly due to trauma; the incidence is not mentioned and the clinical patterns are not described. Acne was apparently aggravated by mining. Psoriasis is stated to be uncommon-less than $0.89 \%$ were affected. Carrié (1951) discussed the increasing incidence of tinea infections in miners.

Sneddon (1951) drew attention to the long period at work (average 15 years in his 59 colliery workers) before dermatitis develops. He considered ageing of the skin to be an important factor in predisposing to dermatitis and suggests that the repeated washing which the miner cannot avoid may also be a contributory factor. Only two of his patients had an occupational dermatitis due to sensitization and in both cases the rubber lining of the pit helmet was responsible.

Atkins and Marks (1952) reported a careful investigation of beat disorders. They were able to demonstrate that the attacks usually resulted from the extension of a staphylococcal infection.

\section{The Miner}

The special working conditions inseparable from the occupation of mining have developed in the miner certain well-defined mental characteristics and the segregation of miners into sometimes isolated communities devoted almost exclusively to mining has accentuated the differences in outlook resulting from the occupation itself. Although improved transport facilities and the government-sponsored development of trading estates in mining districts are tending to break down these differences, the miner still retains many of his traditional attitudes.

The miner's relations with his employers have often been unhappy and for many years such improvements in his working conditions as he was able to obtain followed lengthy industrial disputes. Many of the older miners have known long years of unemployment and insecurity and probably a majority of the younger miners are the sons of such men.

Dickson (1936), writing of his impressions of a lifetime in general practice in a Scottish mining district, noted an increased incidence of peptic ulcer and nervous symptoms among miners. He suggested that the change from individual heaving at piece rates to the noisy monotonous mechanical cutting at shift rates might be in some way responsible. He noted a passive dissatisfaction with the work and insisted that "comfort" in its widest sense is necessary to maintain health.

Halliday (1948), acting as a medical referee under the National Health Insurance Act, made a special examination of 200 miners aged less than 45 and of 200 non-miners in the same age group. Sixty-four per cent. of the miners but only $38 \%$ of the nonminers were disabled by psychoneurotic or psychosomatic conditions. He pointed out that sepsis and inflammation of the skin were a cause of disablement 2.6 times more frequently in miners than in nonminers. In discussing those conditions recognized as of psychosomatic origin, he emphasizes, in addition to personal and economic problems, difficulties in the working environment and knowledge and fears of disease and injury as psychosocial barriers to recovery.

Heron and Braithwaite (1953) applied a small battery of objective tests to 184 colliery workers aged 40 to 50 (76 were working underground). They claim to have shown a greater degree of instability (" psychoneurotic handicap") among underground workers than in surface workers.

Wiesel and Arny (1952) in a psychiatric study of coal-miners in the eastern Kentucky area describe 
a "miner's syndrome" in the miner over 40 , characterized by numerous somatic complaints, a passive dependent attitude, and an outstanding lack of anxiety with rationalizations based on having been exposed to "bad air" or hard work. The younger miner showed more conscious anxiety.

The significance of these observations and opinions is doubtful but it is certain that no study of any condition in the causation of which emotional factors may play some part can afford to ignore the psychosocial aspects of a highly specialized physical and emotional environment.

\section{Skin Hazards of Coal-miners}

The coal-miner is less exposed to specific chemical irritants than workers in many industries, but with increasing mechanization this hazard is assuming greater importance. Miners operating mechanical picks, cutters, and borers are in frequent contact with lubricating oils, and those engaged in maintenance cannot escape occasional contact with fuel oils. The blast of automatic picks sometimes produces contamination of the skin by oil under pressure. Pit props are often treated with creosote, but in some pits metal props are replacing the older wooden type. Men and boys engaged in cleaning and filling lamps are in contact with paraffin. A lime wash is freely used on the gallery walls. Some miners employ paraffin or other grease solvents to clean the hands after work. Many use bar alkali soap for washing.

In deep mines the temperature and humidity may be very high. However, both temperature and humidity can vary greatly in different sections of the same mine, according to the distance from the shaft and the efficiency of ventilation. The relative humidity does not vary directly with the temperature and some deep mines are dry. In others the relative humidity may reach $90 \%$.

Since the introduction of water infusion of the coal face to suppress dust, maceration of the skin of the hands has become more frequent, but it was always common in those mines which were wet from the percolation of water through overlying strata. In some mines there may be several inches of ground water, of which the salt content is variable. Miners sometimes complain that the water in certain mines "stings" or " smarts".

The miner's skin is subjected to trauma in a variety of ways. The hands and forearms are exposed to frequent injury, but the hazard is no greater than that of any heavy manual worker. Friction between the skin and the top of the boot, the gaiters, the belt, the back of the helmet, the battery, and the battery straps may be great and the effect on the skin is accentuated when particles of coal or stone dust are rubbed into the skin in these sites.

Apposed skin surfaces are inevitably rubbed together in any heavy occupation, but the miner may be compelled to work for long periods in unusual postures which may bring into close apposition such surfaces as the forearm and the thigh. Since the introduction of pithead baths in many collieries, some miners wear the same working clothes for too long and their clothes may become harshly abrasive from impregnation with coal dust and oil. Socks in this state may well be a contributory factor in dermatitis of the lower leg and foot. Some miners, still influenced by old superstitions, wear a body belt of coarse wool or do not wash the small of the back. Allergic sensitization to clothing is uncommon, but occasionally some component of the boots or the rubber helmet band is responsible.

It is not known whether the miner's relative lack of exposure to sun is of any significance in making him more susceptible to dermatitis.

\section{Comparison of Dermatitis in Miners and Non-miners}

As a preliminary to a planned investigation into skin disease in miners, the clinical notes of some 103 miners (first series) referred for examination by the Ministry of Pensions and National Insurance were examined and compared with those of 80 patients (second series) employed in other industries in South Wales similarly referred.

It was found possible to arrange the incidence of skin disease in the two groups as follows:(1) Non-occupational, e.g., pyogenic infections such as impetigo, psoriasis, seborrhoeic dermatitis, etc.; (2) occupational or aggravated by occupation; (3) doubtful, where occupational irritation could not be completely excluded, e.g., pompholyx, atopic eczema, folliculitis.

Table 1 relates the incidence to age, and Table 2 shows the incidence of clinical pattern related to age and duration in the two groups. (In this context

TABLE 1

AGE INCIDENCE

\begin{tabular}{|c|c|c|c|c|c|c|c|}
\hline & $\begin{array}{c}\text { Under } \\
19\end{array}$ & $20-29$ & $30-39$ & $40-49$ & $50-59$ & $60-69$ & Total \\
\hline \multicolumn{3}{|c|}{ First series: 103 miners } & 3 & 2 & 1 & 0 & 9 \\
\hline $\begin{array}{l}\text { occupational } \\
\text { Occupational } \\
\text { Doubtful } \\
\text { Tinea pedis }\end{array}$ & $\begin{array}{l}0 \\
0 \\
1\end{array}$ & $\begin{array}{l}5 \\
4 \\
1\end{array}$ & $\begin{array}{c}22 \\
3 \\
1\end{array}$ & $\begin{array}{l}12 \\
3 \\
2\end{array}$ & $\begin{array}{c}20 \\
4 \\
2\end{array}$ & $\begin{array}{l}10 \\
3 \\
1\end{array}$ & $\begin{array}{c}69 \\
17 \\
8\end{array}$ \\
\hline \multicolumn{3}{|c|}{ Second series: 80 non-miners } & & & & & \\
\hline $\begin{array}{l}\text { Non- } \\
\text { occupational }\end{array}$ & & & 7 & 7 & 6 & 2 & 33 \\
\hline $\begin{array}{l}\text { Occupational } \\
\text { Doubtful } \\
\text { Tinea pedis }\end{array}$ & $\begin{array}{l}1 \\
0 \\
0\end{array}$ & $\begin{array}{l}3 \\
1 \\
0\end{array}$ & $\begin{array}{l}7 \\
0 \\
0\end{array}$ & $\begin{array}{l}12 \\
0 \\
0\end{array}$ & $\begin{array}{l}14 \\
0 \\
0\end{array}$ & $\begin{array}{l}8 \\
0 \\
0\end{array}$ & $\begin{array}{c}45 \\
1 \\
0\end{array}$ \\
\hline
\end{tabular}


TABLE 2

DISTRIBUTION OF CLINICAL PATTERNS OF OCCUPATIONAL SKIN DISEASE WITH AVERAGE AGE AND DURATION IN MINERS AND NON-MINERS

\begin{tabular}{l|c|c|c|c}
\hline \multicolumn{1}{c|}{ Site } & \multicolumn{2}{|c|}{ Average Age } & \multicolumn{2}{c}{ Average Duration } \\
\cline { 2 - 3 } & Miners & $\begin{array}{c}\text { Non- } \\
\text { miners }\end{array}$ & Miners & $\begin{array}{c}\text { Non- } \\
\text { miners }\end{array}$ \\
\hline $\begin{array}{l}\text { Hands } \\
\text { Hands, forearms }\end{array}$ & 40 & 45 & $2 \mathrm{yr}$. & $1 \mathrm{yr}$. \\
$\begin{array}{l}\text { Groins, inner thighs, } \\
\text { and calves }\end{array}$ & 46 & 54 & $4 \frac{1}{2} \mathrm{mth}$. & $\begin{array}{c}4 \frac{1}{2} \mathrm{mth} . \\
10 \mathrm{mth} .\end{array}$ \\
$\begin{array}{l}\text { Lower legs } \\
\begin{array}{c}\text { Feet and ankles (ex- } \\
\text { cluding tinea pedis) }\end{array}\end{array}$ & 50 & - & $2 \mathrm{yr}$. & - \\
\hline
\end{tabular}

" duration" is the time during which the patient was assessed.) Figures for tinea pedis are included in Table 1 since it is accepted for injury benefit in miners using pithead baths.

Greatly differing clinical patterns are seen in the two groups, and all these differences are shown in Fig. 1. Oil folliculitis was seen in one miner and three non-miners and there were two cases of chloracne in non-miners.

The figures confirm the experience of others that most cases occur in the $\mathbf{3 0}$ to 50 age-groups, but a further peak in the sixth decade occurs in miners (Nils and Skog, 1953). The recognized high incidence between 45 and 55 years of age has been attributed with little supporting evidence to ageing of the skin. MacCormac (1937) showed a precisely similar curve of incidence in non-occupational eczema.

Accepting the necessary case selection it seems that dermatitis in miners is more common on the lower legs, groins, and thighs than in other sites, whilst in other industries the hands and forearms are more often affected. Squire and others (1950) showed that most cases of dermatitis in the light engineering industry originate on the hands and forearms. The figures of long duration underline the chronic nature of the condition.

These facts stimulated a fuller statistical investigation into the natural history of dermatitis in coalminers of South Wales.

\section{Planned Statistical Investigation}

A proforma was prepared for punch card analysis in consultation with a statistician.

The material consisted of Glamorgan miners and a few from Monmouthshire referred to hospital as out-patients. They were examined by three dermatologists separately, or by two working together. Of 70 proformas completed, only 53 were found suitable for analysis, made up of 33 occupational and 20 non-occupational cases. There were too many essential omissions from the remainder for them to be useful.

More than half of the cases of occupational

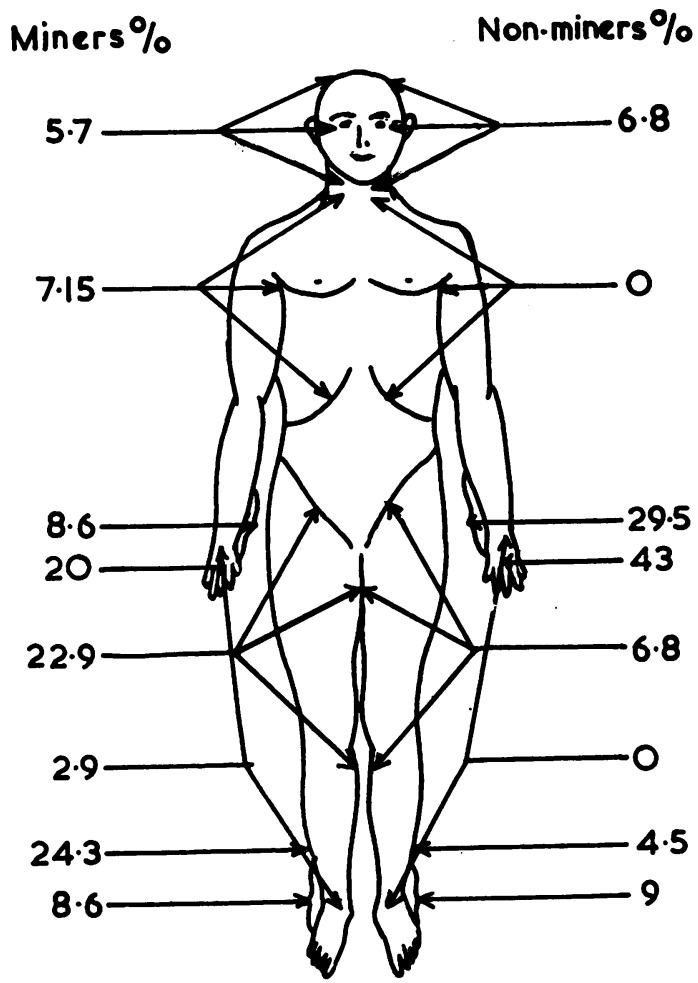

FIG. 1.-Diagram illustrating the distribution of dermatitis in miners and non-miners.

dermatitis occurred in the 40-59 age groups, the peaks of non-occupational cases being in the third and fifth decades.

Distribution of Dermatitis.-The observations of earlier authors were confirmed, as in 16 patients the feet, ankles, or lower legs were first involved; in only nine did the dermatitis begin on the hands or forearms. In several it originated in more than one site. All were occupational cases.

\begin{tabular}{|c|c|c|c|c|}
\hline \multicolumn{2}{|c|}{$\begin{array}{l}\text { Site of Origin of } \\
\text { Dermatitis }\end{array}$} & \multicolumn{3}{|c|}{$\begin{array}{c}\text { Distribution at Time of } \\
\text { Examination }\end{array}$} \\
\hline $\begin{array}{l}\text { Feet } \because \\
\text { Lower legs } \\
\text { Thighs, buttocks } \\
\text { Trunk (belt area) } \\
\text { Neck } \\
\text { Hands and forearms } \\
\text { Other sites } . \\
\text { More than one site . }\end{array}$ & $\begin{array}{ll}\because & 9 \\
\because & 9 \\
\therefore & 3 \\
\therefore & 3 \\
\therefore & 2 \\
\because & 9 \\
\cdots & 1 \\
\cdots & 3\end{array}$ & $\begin{array}{l}\text { Feet and ankles } \\
\text { Lower legs .. } \\
\text { Thighs, buttocks } \\
\text { Trunk } \\
\text { Axillae and groins } \\
\text { Shoulders . } \\
\text { Hands and forearm } \\
\text { Neck. . . } \\
\text { Face, scalp } \\
\text { Generalized }\end{array}$ & $\begin{array}{l}\ldots \\
\cdots \\
\cdots \\
\cdots \\
\ddot{\text { ns }} \\
\cdots \\
\cdots\end{array}$ & $\begin{array}{lr}\ldots & 9 \\
\ldots & 19 \\
\ldots & 6 \\
\therefore & 1 \\
\ldots & 2 \\
\ldots & 4 \\
\ldots & 14 \\
\ldots & 6 \\
\ldots & 2 \\
\ldots & 1\end{array}$ \\
\hline
\end{tabular}

Length of Employment as a Miner.-Twenty-six of 33 miners with occupational dermatitis had worked underground over five years and 15 over 20 years confirming Sneddon's (1951) observations. Since younger men are equally exposed to all 
exogenous causes, contributory factors may include the altered reactions of the skin of the ageing miner, but little is known of the effects on the skin of prolonged exposure to irritants.

Duration of Present Attack.-The duration of the present attack was specified in 31 cases and averaged 11.3 months. In 13 it was less than three months, and in seven exceeded one year. The duration was usually greater in the older miner.

Absence from Work due to Dermatitis.-No fewer than $14(42.4 \%)$ had lost over three months from the present attack (the term " attack" including all spells from recrudescences of first attacks). A quarter lost over one year in attacks. No correlation of duration of absence with age was found and may reflect a greater tendency of the older worker to remain at work through greater financial commitments. A reasonably accurate assessment of the total absence from work is not always easy to obtain and could only be recorded for 30 of the cases.

\begin{tabular}{|c|c|c|c|c|c|}
\hline \multicolumn{3}{|c|}{$\begin{array}{l}\text { Total Time off Work from } \\
\text { Present Attack }\end{array}$} & \multicolumn{3}{|c|}{$\begin{array}{c}\text { Total Absence from Work } \\
\text { (All Attacks) }\end{array}$} \\
\hline $\begin{array}{l}\text { None . } \\
\text { Under } 1 \text { week } \\
2 \text { wk. } 1 \text { mth. } \\
1 \text { mth. } 3 \text { mth. } \\
3 \text { mth. } 6 \text { mth. } \\
6 \text { mth. } 9 \text { mth. } \\
1 \text { yr. }-2 \text { yr. .. } \\
2 \text { yr. -5 yr. . } \\
\text { Not specified. . }\end{array}$ & $\begin{array}{l}. \\
\ldots \\
\cdots \\
\cdots \\
\cdots \\
\therefore\end{array}$ & $\begin{array}{ll}\ldots & 3 \\
\therefore & 2 \\
\therefore & 4 \\
\therefore & 9 \\
\therefore & 3 \\
\therefore & 6 \\
. & 4 \\
. & 1 \\
. . & 1\end{array}$ & $\begin{array}{l}\text { None . . } \\
\text { Under } 1 \text { month } \\
1 \text { mth. } 3 \text { mth. } \\
3 \text { mth. } 6 \text { mth. } \\
6 \text { mth. }-1 \text { yr. } \\
1 \text { yr. }-2 \text { yr. . } \\
\text { Over } 2 \text { yr. .. }\end{array}$ & $\begin{array}{l}\because \\
\because \\
\therefore \\
\therefore\end{array}$ & $\begin{array}{ll}. . & 3 \\
\because & 3 \\
\because & 5 \\
\because & 4 \\
\because . & 8 \\
. . & 3\end{array}$ \\
\hline Total & . & $\ldots 33$ & & & 30 \\
\hline
\end{tabular}

Medical Attention.-Fifty per cent. of 33 cases were referred to a dermatologist within three months of the onset of dermatitis and almost all saw their own doctors within a month. No information was provided of the proportion who remained at work. In seven cases the dermatitis had existed over a year and in $\mathbf{1 0}$ for three to nine months. Earlier specialist advice might reduce the overall period of incapacity. Fifteen patients were idle for over six months and three more were off work over two years from all attacks.

Suggested Causative Factors.-When asked the cause of their dermatitis 19 blamed "oil" and 12 "dust and water".

The tendency among miners, as in other industrial workers, is to attribute all skin disease to occupation, and they are aware that oil is a recognized cause of dermatitis, and that dust and liquids are accepted causes under the National Insurance (Industrial Injuries) Act. Only in one case was oil, in fact, responsible. After our interest in sweating became known this was more frequently suggested by the miner as his own opinion. The dermatologists recorded trauma, friction, water, dust, and heat, as common causes.

Contributory Factors.-Secondary infection was the most important and over-treatment or drug sensitization less than anticipated. The assessment of emotional factors is particularly unreliable. In all cases of dermatitis of the lower leg hypostatic congestion from impaired venous circulation may be an important contributory factor. This is particularly so in the case of the older worker in whom it may prolong the course of a dermatitis initiated by external factors. The assessment of lesser degrees of impaired venous circulation presents many difficulties and we were not able to evaluate its importance in this preliminary investigation.

\section{Summary}

The number of cases annually certified as occupational dermatitis has increased steadily in almost all industries in recent years. This increase is very much greater in mining than elsewhere.

The increasing certification rate may or may not indicate an actual increased incidence.

The literature on skin disease in coal-miners is reviewed.

The known skin hazards of coal-mining are described.

Dermatitis in coal-miners affects mainly the same age groups as in other industries.

Dermatitis in coal-miners involves most frequently the lower legs and the thighs and groins and less often the hands and forearms compared with $70-90 \%$ involvement of hands and forearms in most other industries.

Dermatitis in coal-miners runs a long course, particularly when the groins, thighs, or lower legs are affected.

In only a small minority of cases can occupational dermatitis in coal-miners be attributed to specific irritants and sensitizers are very rarely responsible.

The patterns of dermatitis encountered in miners are consistent with the hypothesis that physical factors-heat, maceration with water, dust, small coal, and trauma-play major roles in their provocation and perpetuation. Soiled and dirty clothes may be important in association. Secondary infection is common and probably of clinical significance.

We should like to thank Dr. G. Lewis-Faning for statistical assistance.

\section{REFERENCES}

Atkins, J. B., and Marks, J. (1952). British Journal of Industrial Medicine, 9, 296

Boëns-Boissau, H. (1862). Traité Pratique des Maladies, des Accidents, et des Difformités des Houilleurs. Tircher, Brussels. 
Carrié, C. (1951). Z. Haut-u. GeschlKr., 10, 48.

Dickson, D. E. (1936). Edinb. med. J., 43, 696.

Dowling, G. B., and Brain, R. T. (1934). Brit. J. Derm., 46, 215.

Flinn, R. H., Seifert, H. S. E., Brinton, H. P., Jones, J. L., and Franks, R. W. (1941); "Soft Coal Miners: Health and Working Environment.; Publ. Hlth Bull. (Wash.), No. 270.

Halliday, J. L. (1948). Psychosocial Medicine. Heinemann, London. Heron, Alastair, and Braithwaite, Dorothy (1953). British Journal of Industrial Medicine, 10, 27.

Heymann, B., and Freudenberg, K. (1925). Morbidität und Mortalität der Bergleute im Ruhrgebiet. Baedeker, Essen.

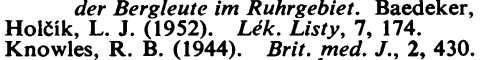

Knowles, R. B. (1944). Brit. med. J., 2, 430.

Kuborn, Hyacinthe (1863). Etude sur les maladies particulières aux ouvriers mineurs employés aux exploitations houilleres en Belgique. Delahaye, Paris.

MacCormac, H. (1937). Brit. J. Derm., 49, 409.
Nils, T., and Skog, E. (1953). Acta derm.-venereol., 33, 466.

Ramazzini, B. (1746). A Treatise on the Diseases of Tradesmen. London.

Rosen, G. (1943). The History of Miners' Diseases. Schuman's, New York.

Schwartz, L., Tulipan, L., and Peck, S. M. (1947). Occupational Diseases of the Skin, 2nd ed. Lea \& Febiger, Philadelphia.

Sneddon, I. B. (1951). Trans. Ass. industr. med. Offrs, $1,142$. Squire, J. R., Cruickshank, C. N. D., and Topley, E. (1950). Brit.

med. Bull., 7, 28. The Effects of Arts, Trades, and Professions,
Thackrah, C. T. (1832). The and of Civic States and Habits of Living, on Health and Longevity, 2nd ed. Rees, Orme, Brown, Green and Longman, London.

White, R. Prosser (1915). Occupational Affections of the Skin.
Lewis, London. Wiesel, C., and Arny, M. (1952). Amer. J. Psychiat., 108, 617. 